\title{
Application of Oncolytic Viruses for Cure of Colorectal Cancer
}

\author{
Della Davis, S. S. Lahiri* \\ Amity Institute of Biotechnology, Amity University, Noida, India
}

Email address:

lahiri1inmas@gmail.com (S. S. Lahiri)

To cite this article:

Della Davis, S. S. Lahiri. Applications of Oncolytic Viruses for Cure of Colorectal Cancer. Cancer Research Journal. Vol. 3, No. 4, 2015, pp. 76-93. doi: 10.11648/j.crj.20150304.13

\begin{abstract}
Colorectal cancer is one of the most commonly diagnosed and lethal cancers worldwide. It is the resultant of multistep processes caused by the accumulation of genetic/epigenetic aberrations. The different therapeutic strategies like radiotherapy, chemotherapy and surgery, used individually or in different combinations, do not remove tumors or their progression all the time. Besides, these procedures involve surrounding cells and tissues. In case of surgery, which is possible only before metastasis, even a single cancer cell left out during surgery, cause further cancer. Focus has been laid in developing agents that could specifically target the cancer cells and leave out the remaining normal cells. This also attempt at total recovery. This was how the focus was laid on viral agents. Over the last two decades, due to various advancements in molecular biology, virotherapy has seen various developments. A special class of viruses called oncolytic viruses have been used as a therapeutic strategy against cancer. These agents have various inherent and engineered factors like enhanced tissue tropism, thereby providing high selectivity; armed with transgenes to deliver therapeutic genes and to perform tumor selective replication, all these factors proving them improved and evolved mechanisms, when compared with other cancer therapeutics. These oncolytic viruses provide greater protection in association with herbal remedies. The purpose of this paper is to provide a detailed account of some of the current observations, developments and insights made in the field of oncolytic virotherapy for targeting colorectal cancer cells. A panel of five oncolytic viruses i.e. adenovirus, herpes virus, reovirus, vaccinia virus and new castle disease virus that are under clinical studies for targeting colorectal cancer cells have been discussed.
\end{abstract}

Keywords: Oncolytic Virus; Colorectal Cancer, Oncolytic Virotherapy, Oncolysis, Targeted Therapy, Adenovirus, CRAds, Herpes Simplex Virus, Reovirus, Vaccinia Virus, New Castle Disease Virus, Immunostimulatory Response

\section{Introduction}

The colon is a tubular structure measuring approx. $1.5 \mathrm{~m}$ in length and varying diameters in an adult. The colon is continuous with the small intestine proximally at the ileocecal valve and ends distally at the anal verge. The rectum, $10 \mathrm{~cm}$ in length in the adult, begins at the peritoneal reflexion and follows the curve of the sacrum ending at the anal canal.

\subsection{Colonic Crypt Organization}

The colon is organized into four histologically distinct layers. The epithelial layer, at the luminal surface, consists of a single sheet of columnar epithelial cells folded into finger-like invaginations that are supported by the lamina propria to form the functional unit of the intestine, called crypts of Lieberkühn (Lc). There are four epithelial cell lineages. The terminally differentiated cells (enterocytes, goblet cells, and endocrine cells), which are found in the top third of the crypt, are derived from multipotent stem cells located at the bottom of the crypt. During asymmetric division, these multipotent cells undergo self-renewal and generate a population of transit amplifying cells that, upon migration upward through the crypt, proliferate and differentiate into one of the epithelial cell types of the intestinal wall. The fourth type of cells, the Paneth cells, differentiates during a downward migration to the base of the crypt, where they reside below the stem cell population ${ }^{1}$.

A variety of functions have been attributed to Paneth cells. These functions include modulation of the intestinal microflora and maintenance of mucosal defense barriers

A normal human crypt contains roughly 2,000 cells and 
approx. 19 stem cells. Stem cells are defined by two functional properties: self-renewal and multipotency. Several molecules have been proposed as markers of stem cells in the intestine, including Musashi-1 (Msi-1), Hes1, integrins $\alpha 2$ and $\beta 1$ subunits, EphB receptors, Bmi-1, Lgr5, and Aldh $1^{2,3}$.

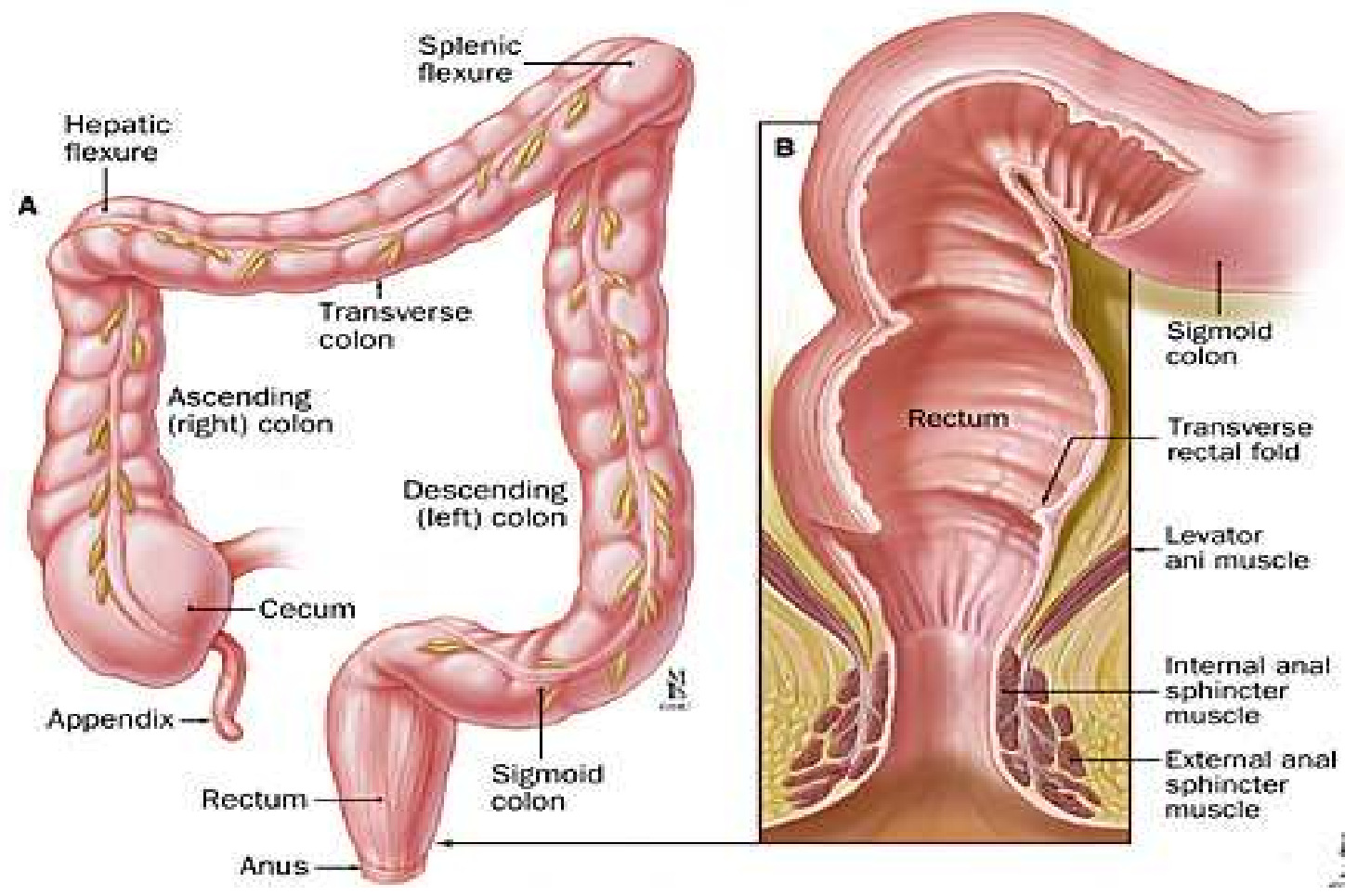

Source:Anatomy of the colon and retum, viewed on $8^{\text {th }}$ July, $2014<$

http://www.hopkinsmedicine.org/gastroenterology_hepatology/diseases_conditions/small_large_intestine/>.

Fig. 1. (a) Anatomy of Colon (b) Anatomy of Rectum.

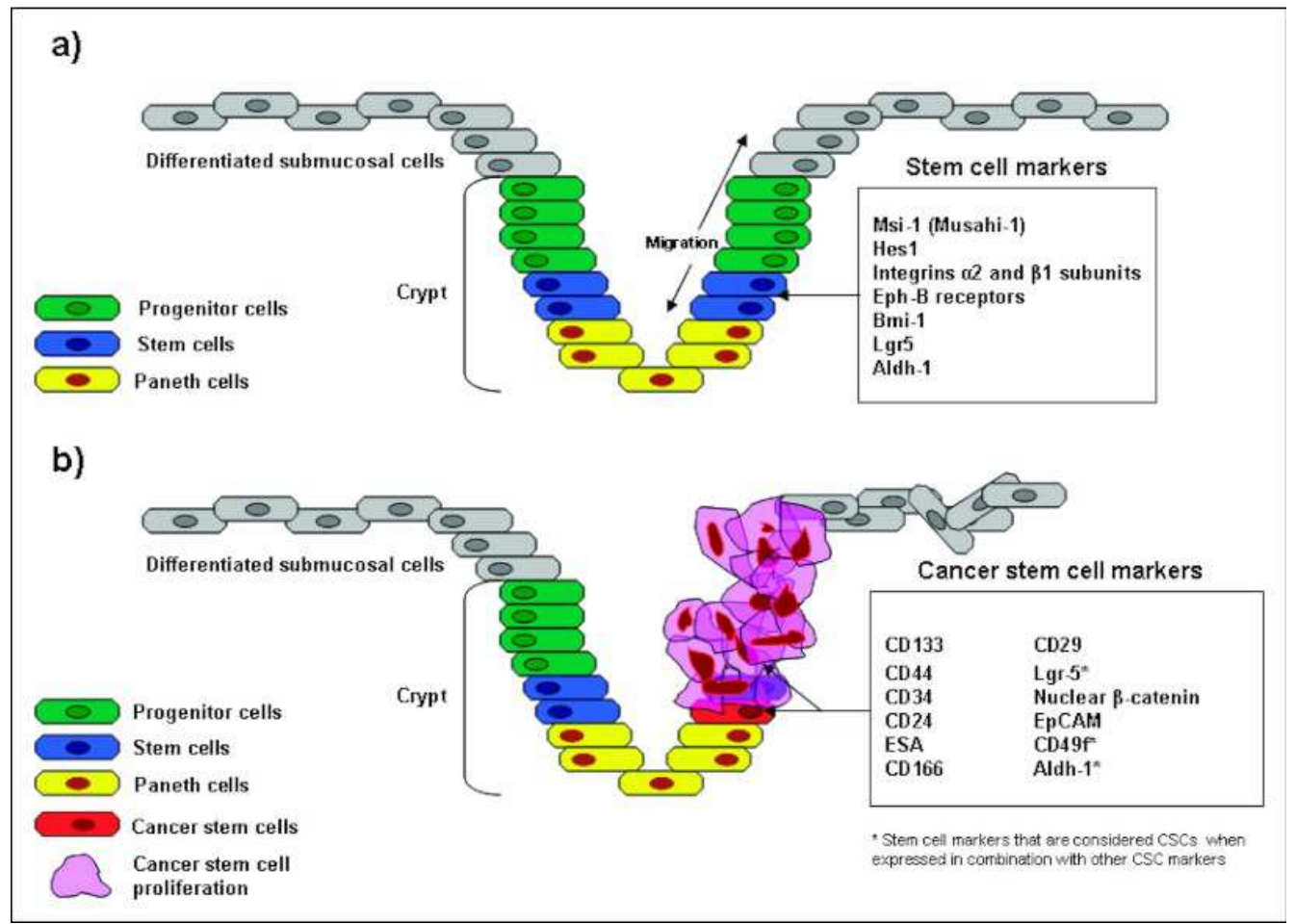

Source: Gastrointest Cancer Res. 2010 Nov-Dec; (Suppl 1): S16-S23.

Fig. 2. This represents the crypt of Lieberkühn, (a) Normal intestinal epithelium (b) Tumorigenic intestinal epithelium. 


\subsection{Colorectal Cancer}

\subsubsection{Epidemiology}

Colorectal cancer (CRC) is the third most common cancer in men (746,000 cases) and the second in women $(614,000$ cases) worldwide. Almost $55 \%$ of the cases occur in more developed regions. There is wide geographical variation in incidence across the world and the geographical patterns are very similar in men and women: incidence rates vary ten-folds in both sexes worldwide, the highest estimated rates being in Australia/New Zealand and the lowest in Western Africa.

The Indian scenario as of 2012 alone is that, there were 64 cases reported with 27 cases in women and 37 cases in men. The mortality figure was high at $49^{4}$. Most of the CRC cases originate from adenomas. The malignant potential of adenomas increases with size, grade of dysplasia, and degree of villous components, along with the number and order of genetic and epigenetic aberrations.

\subsubsection{Growth and Expansion}

Although research was on since 1970s, Michael Bishop ${ }^{5}$ and Harold E Varmus (1985) ${ }^{6}$ first reported the concept of Cellular Oncogene meaning that the responsible oncogenes are already present in every cell. Under conditions of activation of them by any of the physical, chemical or biological agent (mostly viruses), it cause uncontrolled growth, the genesis of cancer.

Most colorectal cancers progress through a series of morphological stages. The earliest histologically recognizable lesion in colorectal cancer formation is the aberrant crypt focus $(\mathrm{ACF})^{7}$. One or more crypts show accumulation of excess cells at the surface. The cells in these aberrant crypt foci may appear normal, forming hyperplastic tissue, or the cells may have abnormal intracellular and intercellular organization, forming dysplastic tissue. As excess cells accumulate, visible polyps grow and protrude from the epithelial surface.

Most polyps remain benign and are often termed hyperplastic polyps. The likelihood that hyperplastic polyps will become cancer is very low and are quite often found to be asymptomatic. Other benign polyps are sometimes referred to as pre-cancerous. These polyps are not malignant themselves, but have a chance of becoming cancerous if not removed. Examples include adenomatous and hamartomatous polyps. The only true malignant polyp is one that has been shown to contain invasive carcinoma. Sometimes the carcinoma is confined to the polyp, and other times it invades one or more layers of the intestine.

Adenomas usually grow on a stalk, resembling small mushrooms. They tend to grow slowly for even a decade or more. The risk of an adenoma developing into cancer increases as the size of the adenoma increases and with the extent of time they have been growing in the colon. Adenomas that are malignant are called adenocarcinomas.

\subsubsection{Transition to Cancer}

When a normal cell undergoes stress or damage, the tumor suppressor protein $\mathrm{p}^{53}$ suppresses cell division or induces apoptosis in response to it. Cancerous growth usually require release from the protective control of $\mathrm{p}^{53}$, over cellular birth and death. The $\mathrm{P}^{53}$ is on the short arm of chromosome 17, region $17 \mathrm{p} 13$. Allelic losses on $17 \mathrm{p}$ occur in less than 10 percent of early or intermediate stage adenomas, increasing to about 30 percent in late adenomas and rising to about 75 percent in cancers. Loss of functional $\mathrm{p}^{53}$ by damage to both alleles drives progression to carcinoma ${ }^{8}$. Other genetic changes during progression cause metastasis and aggressiveness. Migration of the cancerous cells and condition greatly alters the environment in which they live.

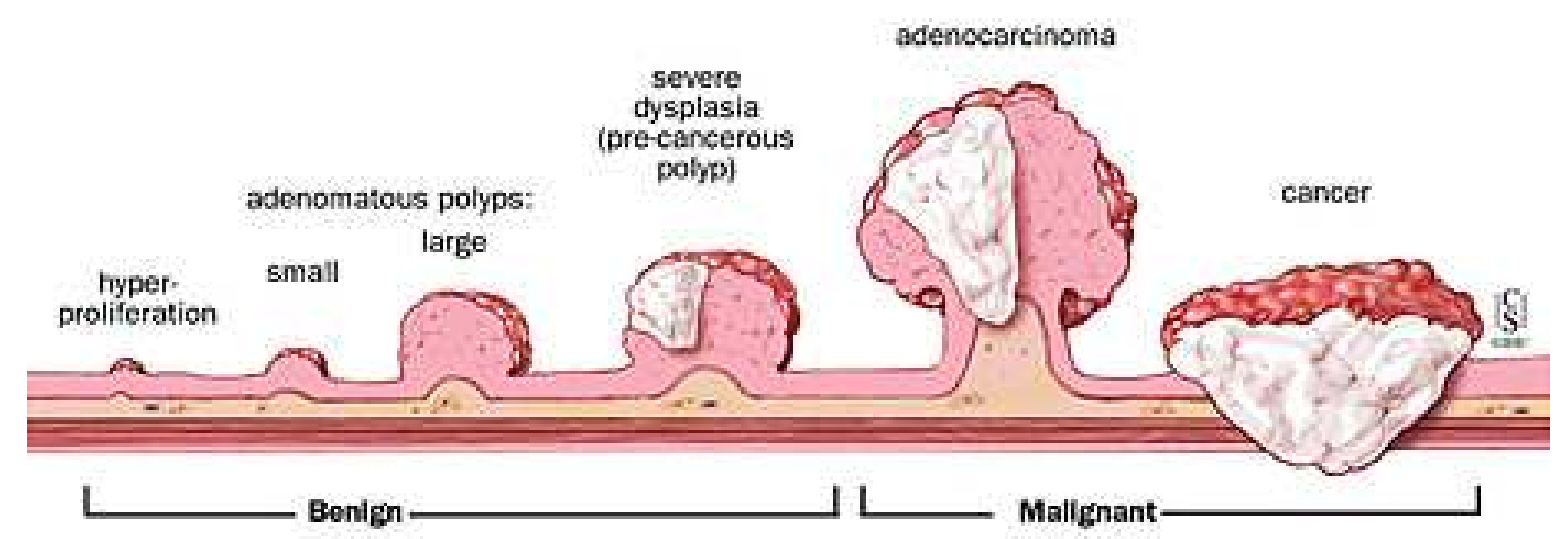

Source: Progression from Polyp to Cancer, viewed on 8th, July 2015, <

http://hopkinscoloncancercenter.org/CMS/CMS_Page.aspx?CurrentUDV=59\&CMS_Page_ID=0B34E9BE-5DE6-4CB4-B387-4158CC924084>.

Fig. 3. Progression of polyp to cancer.

\subsubsection{Molecular Origin}

The genetic events include increases in cellular proliferation and the silencing of genes involved in inhibition of proliferation and apoptosis. The accumulation of mutations involving oncogenes and tumor suppressor genes 
follows the progression of the disease along the adenoma-carcinoma sequence, in which the neoplastic process, initiated by APC or $\beta$-catenin mutations and tumor progression, results from the sequential mutation of other genes, such as K-Ras and $\mathrm{p}^{53}$, in the context of a growing genomic instability.

Cancer is now understood as a heterogeneous group of disorders caused by a set of clonally selected genetic changes or mutations in key tumor-suppressor genes and oncogenes 9 . The different types and subtypes of cancer in a particular organ are determined by the different 'cells of origin'. These cells acquire the first genetic hit or hits that culminate in the initiation of cancer ${ }^{10}$.

Cellular heterogeneity is a histological hallmark of many cancers; tumors are comprised of cells with varied morphological and molecular features. Rare tumor-initiating cells with stem cell-like properties in both hematopoietic and solid malignancies have been identified and classified using distinct cell surface markers. These cancer stem cells (CSCs) can self-renew and differentiate to generate the cellular heterogeneity of the originating tumor ${ }^{11}$.

\subsection{Cancer Therapy: Then and Now}

Until the early twentieth century, surgery was the most practiced form of treatment for cancer therapy. However for those with late diagnosis or inaccessible tumor, survival was rarely reported ${ }^{12}$.

Soon after the discovery of X-rays by Roentgen in 1895 and radioactivity by Marie Curie in 1898 and their subsequent application in cancer treatment, strong and rapid evidence accumulated for radiotherapy, overtaking surgery as a preferred method ${ }^{13}$.

In 1948 chemotherapy blossomed seemingly overnight with the introduction folic acid antagonist aminopterin for the treatment of leukemia. This therapy was the first to bring about regular remissions, chemical compounds for the treatment of cancer became more practiced than radiation compounds or surgical methods. Although hematological malignancies appeared susceptible to many chemotherapeutics, solid tumors were barely affected. As with its predecessor technologies, by the 1950s, reasonable doubts were raised against chemotherapy if it alone would prove a panacea as a cancer treatment ${ }^{14}$.

During the evolution of different therapeutic strategies of surgery, radiotherapy and chemotherapy, used individually and in different combinations of these modalities, it was found that tumors were not removed all the time. Both these practices have their respective side effects like vomiting, diarrhoea, fatigue, hair loss, sexual and reproductive issues etc., owing to their aggressive mechanism of action.

Other forms of therapeutic strategies that were developed over time with technological advancements are immunotherapy, hyperthermia, stem cell transplant, photodynamic therapy and usage of pathogens against cancerous cells ${ }^{15}$.

It was time for more investigation and a return to the pathogens that produced some of the first reports of remission. Combination therapy of acceptable oncolytic viruses with herbal remedies should be attempted as the guideline for the prevention and cure of cancer.

\subsection{History of Oncolytic Viruses}

In 1923, it was reported for the first time that tumors are more susceptible to certain viruses, acting as a sponge attracting viral replication than normal cells ${ }^{16}$.

In 1912, rabies vaccination was thought to modify favorably the course of carcinoma of the cervix. However no considerable proof has been found. Later in 1950s at National Institute of Health (NIH) it was found that adenovirus was able to target and kill HeLa cells in a culture. Oncolytic virotherapy was then included as a part of treatment strategies for cancer and in a study involving cervical cancer patients, it was observed that many tumors had regressed ${ }^{17,18}$.

It was during this time that different chemotherapeutic drugs were developed and popularized by doctors all over the world despite their toxicities and was practiced above virotherapy.

Towards 1980s, with the advent of reverse genetics technology brought about a renewal of interest in virotherapy that allowed the generation of more potent, tumor-specific oncolytics that can over ride the host immune system ${ }^{14}$. Surface protein modifications were done on the capsid to achieve tumor targeting, enhance infectivity and potency ${ }^{19}$.

Now over the last two decades virotherapy has seen various developments. Virotherapeutics which are therapeutic oncolytic viruses are a class of anticancer agents that are targeted to have improved and evolved mechanisms of action when compared with other cancer therapeutics like radiation and chemotherapeutics. Compared to the crude methods practiced in the $1950 \mathrm{~s}$, now virotherapeutics use in vitro-passaged strains (first generation), to genetically engineered selectivity-enhanced viruses (second generation) and finally to genetically engineered transgene-expressing 'armed' oncolytic viruses (third generation) ${ }^{20}$.

Carefully monitored clinical trials followed with many success stories to tell. Even though most of the viotherapeutics are still in initial stages of the trials, some have cleared the phase III and are commercially available in particular countries such as Gendicine and Oncorine approved by China for head and neck cancer ${ }^{21}$.

Oncolytic virotherapy is a promising form of gene therapy for cancer, employing nature's own agents to find and destroy malignant cells. The purpose of this review is to provide a detailed account of this field of research and bring forth some of the current observations, insights and ideas circulating in the literature. We have strived to cover as many different oncolytic viruses as possible to give a broader picture of targeting colorectal cancer cells using these viruses.

The panel of oncolytic viruses include the avian adenovirus, foamy virus, myxoma virus, yaba-like disease virus, echovirus type-1, bovine herpesvirus-4, Saimiri virus, feline panleukopenia virus, Sendai virus and the non-human 
coronaviruses $^{22}$.

However in this paper only the viruses that target colorectal cancer cells would be dealt with i.e. adenovirus, herpes virus, reovirus, new castle disease virus and vaccinia virus.

Although promising, virotherapy still faces many obstacles that need to be addressed, including the emergence of virus-resistant tumor cells.

\section{Review of Literature}

\subsection{Selection Criteria for Virotherapy}

Due to widely differing structures, lifecycles mechanisms and cellular tropisms of different viruses, resulting in highly distinctive clinical manifestations, specific oncolytic viruses would be ideally suited to a specific malignancy. Most of the oncolytic viruses currently in development show a relatively broad spectrum of antitumor activity, such as oncolytic adenoviruses were initially considered for therapy of epithelial malignancies but now are also studied against hematologic cancers; similarly HSV and measles virus are considered for other malignancies apart from what they were originally found for.

Viruses are designed in a particular fashion to target specific cell surface receptors or nuclear transcription factors and their utility is hence limited to tumors that express the relevant target molecule. However due to safety issues, broad spectrum antitumor activity is preferred in clinical studies, and in a downside study, it was found that they get attenuated when they reach their target. Thus all the assumptions regarding safety and host range need to be tested experimentally in appropriate animal species.

Another major concern is the toxicity levels that change with every genomic manipulation. Some of the factors carefully monitored are virus tropisms, mutability, anti-apoptotic and cytotoxic gene products, anti-viral immunity and drug availability to remove any unwanted products $^{23}$. The safety considerations that need to be checked while using an oncolytic virus include cancer specificity, regaining pathogenecity, transmissibility, undesired side effects and pre-existing immunity. In order to overcome most of the risks included, non-human viruses are preferred for oncotherapy.

Efficacy of virotherapy is determined by its ability to overcome the host antiviral immune response system. This includes mechanisms such as serotype switching and polymer coating even if the immune system is invoked, the antibody cannot distinguish the virus particle and use of cellular vehicles ${ }^{24,25}$.

The identification of a suitable tumor-specific antigen is one of the most important steps in developing immunotherapeutic treatments. Till date four different markers, Carcinoembryonic antigen (CEA), MUC1, Guanylyl cyclase $\mathrm{C}^{26,27,28}, \mathrm{KRAS}^{29,30}$ and $\mathrm{Tp}^{5331}$, have been studied extensively with wide applications which have been explained later.

\subsection{Adenoviruses}

The human adenoviruses (Ads) belong to the Mastadenovirus genus in the family Adenovirus which are unusually stable to chemical or physical agents and adverse $\mathrm{pH}$ conditions, allowing for prolonged survival outside of the body. The icosahedral structure of the adenovirus has a capsid of 252 capsomers covering 36kbp linear dsDNA. There are over 50 defined Ad serotypes, grouped A-F differing at various levels (e.g. pathology in humans and rodents, hemagglutination properties, target cell receptors) and these differences (outside of fiber substitutions) have been largely ignored as potential means to develop more potent oncolytic $\mathrm{Ads}^{32,33}$. Even though as monotherapies, oncolytic human adenoviruses have shown limited clinical efficacy, they are envisioned as novel, replication-based treatments for human malignancies. Various principles have been employed such as Directed Evolution to generate highly potent Ads with specific altered properties such as efficiency of cell lysis, infectivity, and viral DNA replication or by arming therapeutic viruses with therapeutic transgenes ${ }^{34}$.

Despite their theoretical promise, the reality is that oncolytic viruses have had limited clinical success as monotherapies perhaps due to an imbalanced focus on safety over potency. Recently however, there are several late stage clinical trials showing promise which may eventually lead to clinical acceptance ${ }^{35}$.

\subsubsection{Mode of Action}

For most of the serotypes Ad infection is initiated by the fiber knob domain binding to a cell surface receptor CAR (coxsackie-Ad receptor) which causes the penton base to interact with the integrins. This receptor ligand interaction induces endocytosis of the virus into the cell. The viral genome is released into the nucleus of the cell resulting in selective expression of viral proteins in early phase and genome replication followed by expression of late genes in late phase. The late phase is followed by assembly and maturation of the virus triggering cytolysis and release of viral progeny.

During the early phase of infection, transcriptional activator E1A is the first gene expressed which interacts with retinoblastoma protein $(\mathrm{pRb})$ and induces cell cycle entry, thus promoting viral replication. However it also activates the apoptosis pathway.

E1B-55kD and E1B-19kD protein units bind to $\mathrm{p}^{53}$ and degrade it, thereby acting as anti-apoptotic factor; together prevent the death of the infected cell allowing viral replication to occur. Other early genes encode proteins required for: viral DNA synthesis (E2); regulation of viral DNA replication, mRNA transport and apoptosis (E4); and host immune suppression and cell lysis (E3). The delayed and late genes encode viral structural proteins and the proteins necessary for virus assembly.

Ads as gene therapy vectors

The first barrier in vector engineering for cancer therapy is enabling it with a dose of the therapeutic gene(s) to be delivered to and expressed in the diseased tissues with high 
efficiency, specificity and safety. Some advantages have made Ads one of the most widely used gene transfer vectors today are

1. High infectivity of most mammalian cell types (both dividing and quiescent), high transgene(s) expression level

2. Ease of achieving high virus titer and replication deficiency

3. Large capacity for accommodating transgene(s) and non-integration into the mammalian genome

Some of the barriers faced using this are:

4. Ads are highly immunogenic inducing strong host immune responses that can rapidly eliminate transgene expression.

5. The epichromosomal status of the vector genome within the host causes a low expression of transgene bringing it as a shortfall for long term gene therapy.

6. Also the primary receptor for Ads, CAR, is poorly expressed in tumors resulting in resistance of some tumors to Ad infection.

Some of the strategies to overcome these barriers include

1. Deletion of more Ad genes, from E1 and E3 to E2 or/and $\mathrm{E} 4$, to reduce immunogenicity, such as preparing a 'gutless' Ad, which is made devoid of all viral coding regions. This new generation Ad vector elicits a much reduced in vivo immune response in animal models and prolongs transgene expression, while maintaining relatively high transduction efficiency and wide tropism.

2. Replication-defective Ads have been commonly used to transfer tumor-suppressor genes, anti-angiogenic factors, prodrug-activating genes and immunostimulatory genes.

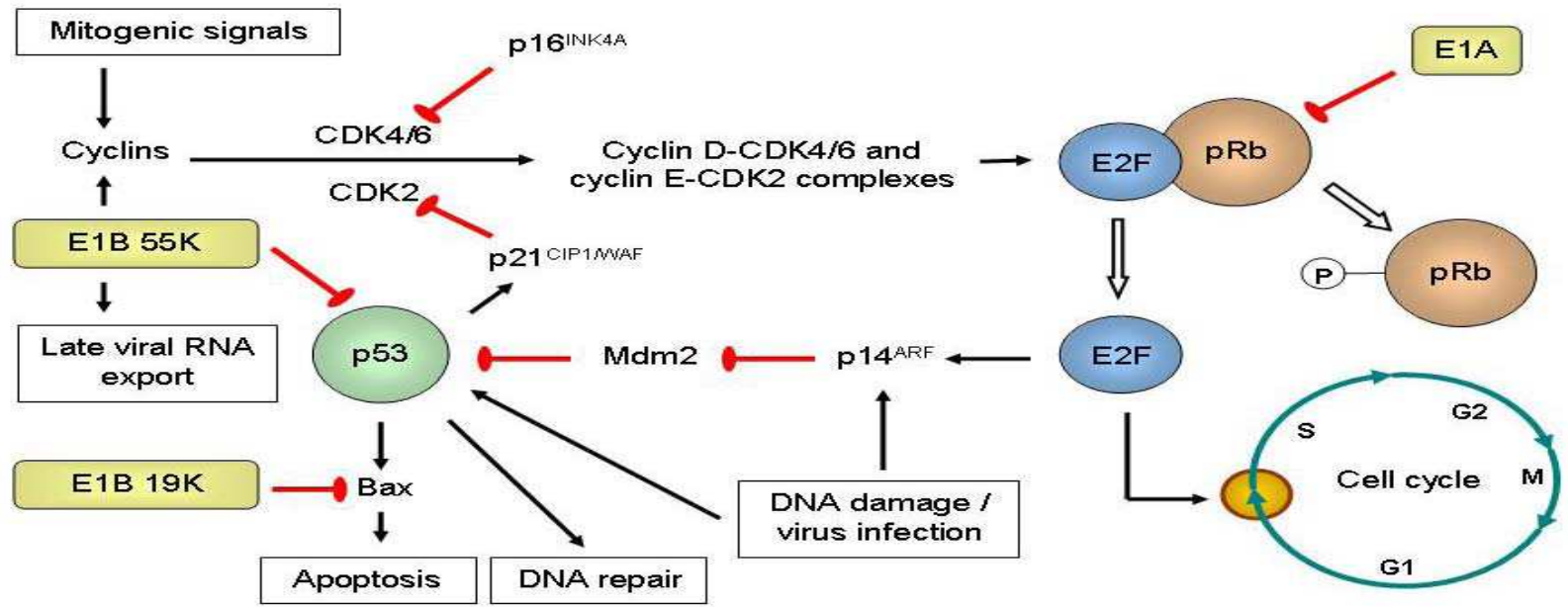

Sources: Viruses 2.1 (2010): 78-106

Fig. 4. Engineered replication selectivity of oncolytic adenoviruses (Ads).

Table 2.1. Therapeutic genes transferred by adenoviral vectors.

\begin{tabular}{|c|c|c|c|}
\hline Main types & Genes & Target/mechanism & Cancer \\
\hline $\begin{array}{l}\text { Tumor-suppressor } \\
\text { genes }\end{array}$ & Including p53, Rb, p16, PTEN, p21, p27 & $\begin{array}{l}\text { Repair defects caused by loss of } \\
\text { tumor-suppressor genes. Induce apoptosis, } \\
\text { block proliferation and metastasis of tumor } \\
\text { cells }\end{array}$ & $\begin{array}{l}\text { Head and neck, lung, melanoma, } \\
\text { prostate, breast, thyroid, ovary, } \\
\text { colon, bladder, gliomas, etc. }\end{array}$ \\
\hline $\begin{array}{l}\text { Immunostimulatory } \\
\text { genes }\end{array}$ & $\begin{array}{l}\text { Cytokines (e.g. IL-2, IL-12, TNF-, GM-CSF); } \\
\text { Tumor antigens (e.g. CEA, EGFR); immune } \\
\text { accessory molecules (e.g. B7) }\end{array}$ & $\begin{array}{l}\text { Enhance systematic immune function, } \\
\text { immunogenicity of tumor cells and anti-tumor } \\
\text { immunity }\end{array}$ & $\begin{array}{l}\text { Solid tumors (e.g. melanoma, } \\
\text { colon, breast, prostate), leukemia, } \\
\text { etc. }\end{array}$ \\
\hline $\begin{array}{l}\text { Antigens for tumor } \\
\text { vaccines }\end{array}$ & $\begin{array}{l}\text { Tumor-associated antigens (e.g. hMUC1, } \\
\text { HPV-E7, HER2/neu, IFN-, etc.), or } \\
\text { co-expressed with other immunostimulatory } \\
\text { genes (e.g. IL-2, TNF, etc.) }\end{array}$ & $\begin{array}{l}\text { Readjust the host immune system to be more } \\
\text { sensitive to a specific, but often weakly } \\
\text { immunogenic tumor-associated antigen, for } \\
\text { cancer treatment and prevention }\end{array}$ & $\begin{array}{l}\text { Cervix, prostate, breast, } \\
\text { melanoma, colon, etc. }\end{array}$ \\
\hline $\begin{array}{l}\text { Prodrug-activating } \\
\text { genes }\end{array}$ & HSV-TK/ganciclovir, CD/5-fluorocytosine, etc. & $\begin{array}{l}\text { Express enzymes that convert a nontoxic } \\
\text { substance (prodrug) into a cytotoxic molecule } \\
\text { for suicidal killing of cancer cells }\end{array}$ & $\begin{array}{l}\text { Ovary, brain, colon, prostate, } \\
\text { mesothelioma, cervix, etc. }\end{array}$ \\
\hline Other genes & TNF-, E1A, anti-MDR1 ribozyme, etc. & $\begin{array}{l}\text { Induce tumor cells to become susceptible to } \\
\text { radiotherapeutics, revert multidrug resistance of } \\
\text { tumor cells, etc. }\end{array}$ & Breast, rectum, liver, etc. \\
\hline
\end{tabular}

Source: Cancer gene therapy 14.7 (2007): 599-615. 
Ad-based antisense/small interfering RNA therapy

In order to achieve gene silencing using Ad vectors, two different approaches have been developed.

1. The antisense RNA for the targeted gene is produced after transfection resulting in the subsequent knockdown of the targeted message. Ads simultaneously expressing both antisense ornithine decarboxylase and adenosylmethionine decarboxylase inhibit colorectal cancer cell growth in vitro.

2. Using the principle of RNA interference (RNAi) for gene silencing Ad vectors are being employed to deliver small interfering RNA (siRNA) molecules in the form of short hairpin RNAs (shRNAs) effectively silencing endogenous TGF- $\beta$ RII.

\section{Ad-based cancer vaccines}

Ad is often chosen as the vector to carry cancer cell-associated antigens and/or other immunostimulatory cytokines to design gene-based cancer vaccines.

Several viral vector vaccines have been explored for CRC treatment in clinical trials. Recombinant poxviral vectors expressing CEA and its various co-stimulatory molecules have been explored since the 1990s with very uninspiring results. In contrast, GUCY2C-targeted vaccination is in early stages of development. An adenoviral vector expressing the extracellular domain of GUCY2C (Ad5-GUCY2C) induces GUCY2C-specific immune responses as well as prophylactic and therapeutic immunity against metastatic colorectal cancer in mice without adverse effects ${ }^{36,37}$.

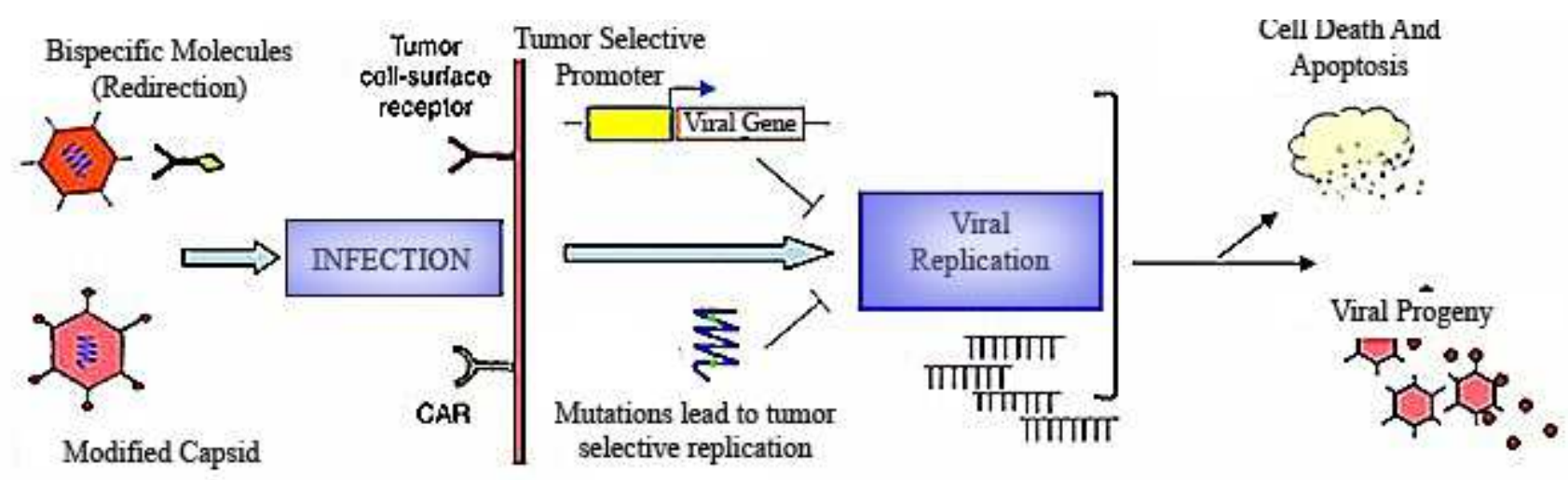

Source: Cancer gene therapy 14.7 (2007): 599-615.

Fig. 5. Strategies of accomplishing Ad tumor selectivity.

\subsubsection{Modifications to Improve the Targeting of Ad Vectors}

1. Modification of the capsid fiber and penton base protein for targeting

The viral tropism could be determined by genetically modifying the surface proteins involved the capsid formation specifically the capsid fibre, the penton base and protein IX (pIX). During tissue receptor binding, the capsid fibre binds to CAR receptor of tissue inducing the penton base to recruits $\alpha \beta$ integrins via an RGD (Arg-Gly-Asp) motif resulting in internalization of the virion via receptor-mediated endocytosis.

2. Modification of capsid pIX for specific targeting pIX is an abundant (240 copies) and small polypeptide (140 residues) on Ad capsid and contributes to structural and thermal stability, Ad DNA packaging and as viral and cellular transcriptional activator. However since it is exposed on the outer surface it could be genetically altered to target cell surface receptors.

3. Bi-specific adapter for Ad targeting

A bi-specific adapter having a capsid binding domain and a cell surface receptor domain could be used to effectively re-direct Ad to transduce cells expressing the targeted receptor in a CAR-independent manner. Eg: sCAR-EGF, bi-specific antibodies against fiber and EGFR.

4. AAV/Adv 'cocktail' vector system
The major strengths and limitations of Ad and AAV vectors are complementary. An AAV/Ad 'cocktail' vector strategy was taken wherein it was shown that addition of a low level of Ad-bone morphogenetic protein 2 (BMP2) to AAV-BMP2 produced significantly higher new bone formation than the use of AAV-BMP2 alone in the rat model.

\subsubsection{Oncolytic, Conditionally Replicative Ads (CRAds)}

The selectivity of CRAds is crucial for its tumor-specific targeting which are achieved either during infection or during replication. Depending on different mechanisms by which CRAds achieve selectivity, they can be divided into four classes:

\section{Tumor-selective infection}

This is achieved by altering the viral surface proteins or providing bi-specific ligands or adaptors (e.g. SCAR-EGF, bi-specific antibodies against fiber and EGFR) so as to manipulate capsid and target tumor cell interaction.

Tumor-selective replication

This is achieved by altering genes encoding viral replication proteins such that the viral replication would occur only in tumor cells with abnormal pathways such as $\mathrm{p}^{53}$, p16/RB and RAS/PKR or IFN/PKR, thereby leaving out the normal cells. For example, the CRAd prototype ONYX-015 is able to replicate only in $\mathrm{p}^{53}$ deficient tumor cells.

Tumor-selective promoters 
Using the strong promoters that otherwise cause the up-regulation of genes such as AFP, CEA, TERT etc., to control the expression of viral replication proteins, would result in increase in viral replication by 10,000 -folds in tumor cells while showing minimal toxicity to normal cells.

\subsubsection{Adenoviral Strains Currently Under Clinical Studies} ONYX-015

In current clinical application, ONYX-015 is an adenovirus with the E1B 55-kDa gene deleted, engineered to selectively replicate in and lyse $\mathrm{p}^{53}$-deficient cancer cells while sparing normal cells. Although ONYX-015 and chemotherapy have demonstrated anti-tumoral activity in patients with recurrent head and neck cancer, disease recurs rapidly with either therapy alone. During a phase II trial of a combination of intra-tumoral ONYX-015 injection with cisplatin and 5-fluorouracil in patients with recurrent squamous cell cancer of the head and neck, a high proportion of complete responses observed for 6 months, where none of the responding tumors had progressed, with acceptable toxic effects $^{38,39}$.

ColoAd 1

ColoAd1 is a novel Ad3/Ad11p chimeric oncolytic virus for the treatment of human colon cancer was shown to be more potent and have a larger therapeutic window than Ad5 and the most clinically advanced oncolytic virus Onyx-015. This virus has several changes relative to the parent Ad11p virus to enhance the tumor selectivity and host cell lysis ${ }^{40}$.

The viral DNA replication genes from the E2B region of Ad5 together with the smaller genome, this virus replicates reaching the critical viral burst size more rapidly, consequently enhancing viral lysis and spread.

1. The protein CAD which is an over expressed TP-nuclear matrix association protein in tumor cells, is targeted by the pre-terminal protein (pTP) of Ad5 providing target selectivity.

2. In order to track the progress of virotherapy, genes associated with radionuclide imaging is also engineered into the genome of the virus delivered.

ColoAd1 utilizes the tumor surface cell receptor CD46 in order to facilitate selectivity since it is over expressed in tumor cells even in higher grades of tumor unlike other Ad5 receptors like CAR receptor (coxsackie B- and adenovirus receptor $)^{41}$.

In vivo, ColoAd 1 shows attenuated and little or no activity by either cytotoxicity or by qPCR efficacy following intra-tumoural, intravenous and intra-peritoneal injection to systemically deliver immunomodulatory antibodies, such as anti-VEGF antibodies, into immunodeficient mouse human tumour xenograft models. Anti-VEGF antibody expression by these tumors could be detected in the tissue as both mRNA and functional antibody ${ }^{42}$.

\subsection{Herpes Simplex Virus}

The herpesvirus family consists of a group of viruses distinguished by the large size of their linear double-stranded DNA genomes ( $\sim 130-250 \mathrm{kbp})$ and a common architecture of infectious particles. Based on their biological properties such as growth characteristics and tissue tropism, herpesviruses can be further divided into three subfamilies. Among the eight human herpesviruses, the alpha subfamily includes neurotropic viruses and contains the herpes simplex virus (HSV) 1 and 2, and Varicella zoster virus (VZV) ${ }^{43}$.

$\mathrm{HSV}$ is a double-stranded DNA virus encoding more than 84 different polypeptides. HSV DNA consists of two unique sequences: Unique Long (UL) and Unique Short (US), which are separated by terminal inverted repeats.

Gene-modified HSV includes inactivation of ICP6 gene and deletion of $\gamma$-34.5. ICP6 is essential for viral DNA replication and gene $\gamma 34.5$ is the major neuropathogenicity gene in HSV. As a consequence of genetic modification, ICP6/ $\gamma 34.5$-deleted HSV imposes low pathogenicity to normal tissue and high oncolytic capacity to tumor cells. Multi-gene deletions confer great selectivity and safety on $\mathrm{HSV}$; however, deletions of mutations lead to a reduction in neurovirulence and clearness of the virus by host immune response.

\subsubsection{Mode of Action}

An organ culture system was developed from colon carcinoma and healthy colon tissues of mouse and human origin and was infected with HSV-1 at a very low efficiency, in contrast to high-efficiency infection of colon carcinoma tissue. It was found that two extracellular components, collagen and mucin molecules, were found to restrict HSV-1 infectivity in the healthy colon. The mucin layer of the healthy colon binds to HSV-1 and thereby blocks viral interaction with the epithelial cells of the tissue. In contrast, colon carcinomas express small amounts of collagen and mucin molecules and are thus permissive to HSV-1 infection. In agreement with the ex vivo system, HSV-1 regresses the volume of the tumor ${ }^{44}$.

Arming HSV with therapeutic genes 


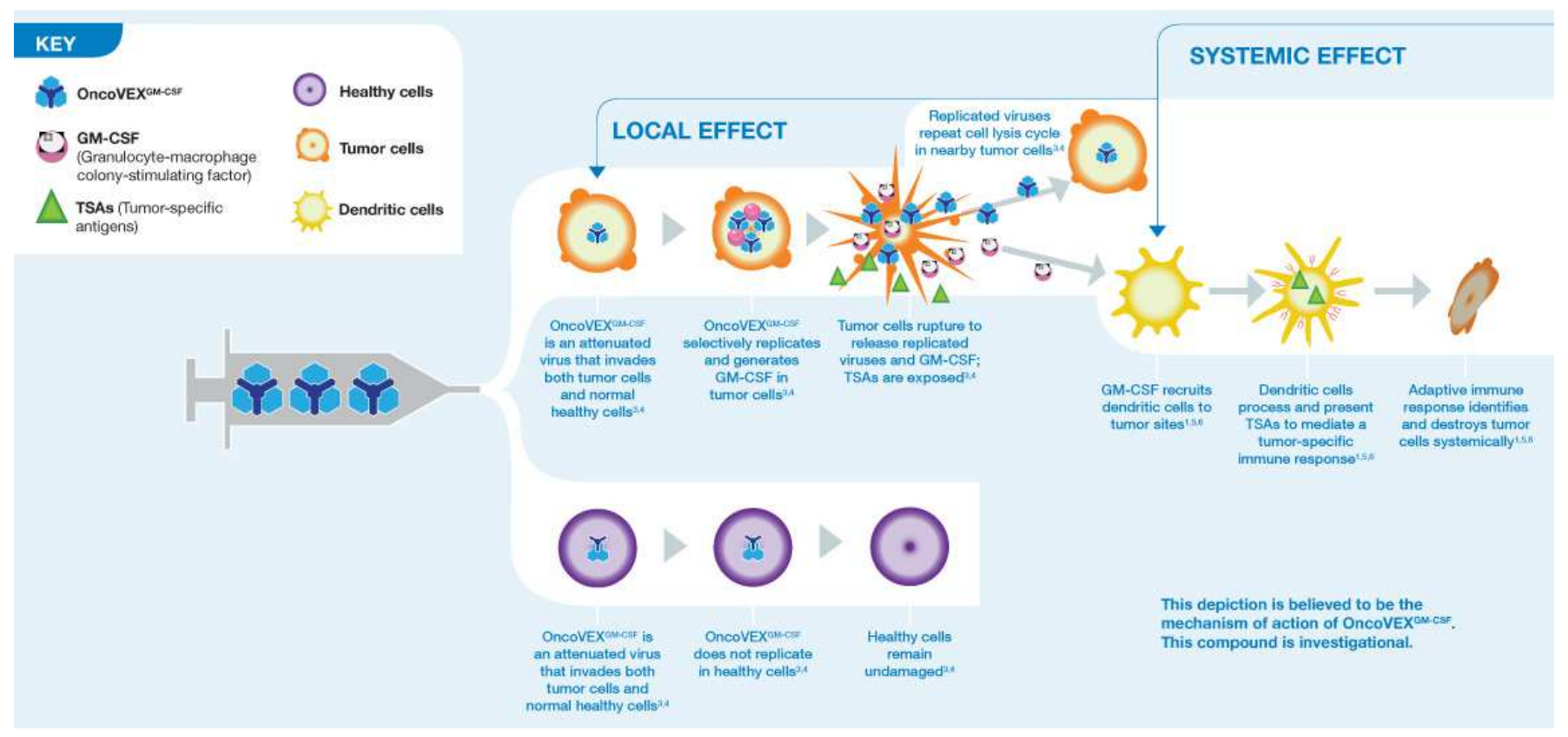

Source: OncoVEX ${ }^{\mathrm{GM}-\mathrm{CS}}$ Amgen Inc, viewed on $8^{\text {th }}$ July, $2015<$ Amgen Inc http://www.amgenoncology-international.com/\#/our-science/oncolytic-immunotherapy/>.

Fig.6. Mode of action of OncoVex GM-CSF.

Accounting to the large genome, HSV-1 can accommodate a variety of therapeutic genes such as suicide genes, cytokines, chemokines, immuno-stimulatory molecules or tumor suppressor genes which can induce an inflammatory response. For example, NV1042 delivers immuno-modulatory molecule is IL-12 which can invoke CTLs, helper T lymphocytes and NK cells has shown significant anti tumor effects on murine model of micro-metastatic liver disease. Similarly, OncovecGM-CSG expresses a Granulocyte macrophage colony-stimulating factor (GMCSF) gene which activates $\mathrm{T}$ cells to exert a cytotoxic effect on the tumor cells.

\subsubsection{HSV Strains under Clinical Studies \\ G207 and G47 delta}

The first oncolytic HSV-1 studied in clinical trials in the US, G207 has deletions of two copies of the $\gamma-34.5$, insertion of an E.coli $\mathrm{LacZ}$ gene and an intact thymidine kinase gene derived from HSV, contributes increased cytotoxic $\mathrm{T}$ lymphocyte activity resulting in improved anti tumor immunity.

The US11 gene involved in replication of the virus, is placed under the control of the strong immediate-early $\alpha 47$ promoter, thereby bringing forward the G47delta strain. Also, the $\alpha 47$ promoter increases the expression of MCH-I, thereby improving the tumor antigen presentation.

NV1020

NV1020 is derived from HSV-1 with a deletion in UL/S junction $(\alpha 0, \alpha 4$ and $\gamma 134.5)$, one copy of UL56, thymidine kinase (TK) gene and addition of the promoter for the gene UL24 and an exogenous copy of TK gene placed under control of the ICP4 promoter enabling its attenuation so that it could replicate only in a tumor cell ${ }^{45}$. Clinical studies with patients having colorectal adenocarcinomas metastatic to the liver showed major reduction in tumor size when administered intravenously in conjugation with chemotherapy ${ }^{46}$.

Limitations of using HSV:

1. They can only produce one particular mediator and thus their oncolytic effects are limited.

2. It is difficult to control the amount of cytokine and there is a risk of excessive cytokine expression

3. Latent infection is possible with native virus

\subsection{Reovirus}

Reovirus belongs to the Reoviridae family, which includes viruses of a variety of tropisms (with examples of animal-, plant-, and insect-pathogenic viruses) and, most notably, the major human pathogen, rotavirus. Unlike the clinically significant rotavirus, reovirus is relatively nonpathogenic in humans. There are three serotypes of reovirus, based on their hemagglutination-inhibition activity, found ubiquitously in environment. Prototypical laboratory strains of each serotype were isolated from children's respiratory and enteric tracts and are designated Type 1 Lang, Type 2 Jones, Type 3 Abney, and Type 3 Dearing $^{47}$. These viruses have a non-enveloped icosahedral capsid, core and a nucleoprotein complex. The capsid, 60-8-nm in diameter, has a double protein shell. The genome consists of linear double stranded RNA $18 \mathrm{~kb}-30 \mathrm{~kb}$ long packed within each virion.

\subsubsection{Mode of Action}

When a viral surface protein binds to the extracellular domain of EGFR, it stimulates a tyrosine kinase activity of the receptor which in turn auto-phosphorylates EGFR's cytoplasmic tail. Phosphotyrosine binding adapter molecules, such as Grb2, are recruited to the tail which recruits the protein 
Sos to the plasma membrane, where it stimulates the exchange of GTP for GDP on the small G protein, Ras. Ras-GTP can cause constitutive activation of signaling pathways downstream of Ras, such as the mitogen-activated protein kinase (MAPK) and the stress-activated, c-Jun $\mathrm{NH}_{2}$-terminal protein kinase (SAPK/JNK) cascade, are implicated in cellular transformation and progression toward cancer.

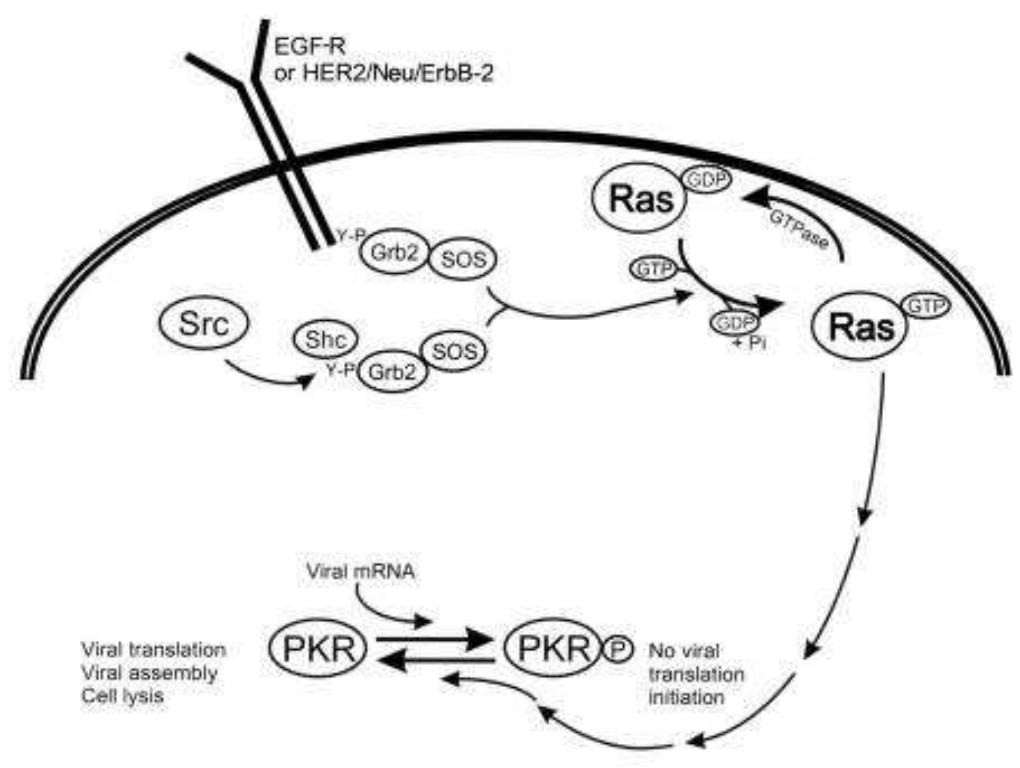

Source: J Clin Invest. 2000;105(8):1035-1038. doi:10.1172/JCI9871.

Fig. 7. Usurpation of the Ras signaling pathway by reovirus.

Reovirus can take advantage of the constitutive tyrosine kinase activity of the truncated EGF-R in tumor cells. Ras signals may sensitize cells to reovirus by blocking cellular defences against viral infection.

In untransformed cells, double-stranded RNA structures in these early transcripts then stimulate the cellular antiviral defense mechanism, initiated by activation of the double-stranded RNA-activated protein kinase PKR which eventually prevents the initiation of translation of viral transcripts. Viral protein synthesis is thus blocked, the replication cycle is halted, and the cell survives. In cells with activated Ras pathway signaling, however, PKR phosphorylation and activity are impaired and viral translation ensues. The lytic cycle can then proceed: secondary transcription and translation occur, and final particle assembly ultimately precedes death of the transformed cell. Cells in which PKR expression is knocked out behave just as Ras-transformed cells, substantiating the necessity of PKR in the antiviral response of normal cells.

So far, more than $80 \%$ of human tumor cell lines of various origins have proved to be infectible and the use of SCID mouse models and human cancer cell lines (including breast, prostate and colorectal cancer) showed positive results for tumor xenografts.

\subsubsection{Reoviral Strain Currently Under Clinical Study Reolysin}

It is a wild type strain of Type 3 Dearing reovirus developed by Oncolytics Biotech. Reoviral infection in normal cells causes activation of cellular PKR (dsRNA-activated protein kinase) and aborting of viral protein translation and replication In tumor cells, PKR was found to stay inactivated and unable to arrest viral translation, replication, and cytolysis. This mechanism increases the succeptibility of Ras pathway by utilizing the over expression of upstream elements of Ras gene such as EGFR or $\mathrm{PDGFR}^{48}$. It was also found to show selective replication in KRas transformed human epithelial cells in cell lines study. Reolysin could be used in conjugation with tunicamycin or brefeldin whose proteasome inhibitor causes enhanced ER stress-mediated apoptosis ${ }^{49}$. Reovirus has been evaluated in murine and humans via the intratumoral and intravenous route resulting in tumor regression with mild toxicities and consisted of transient flu-like symptoms and headache. 


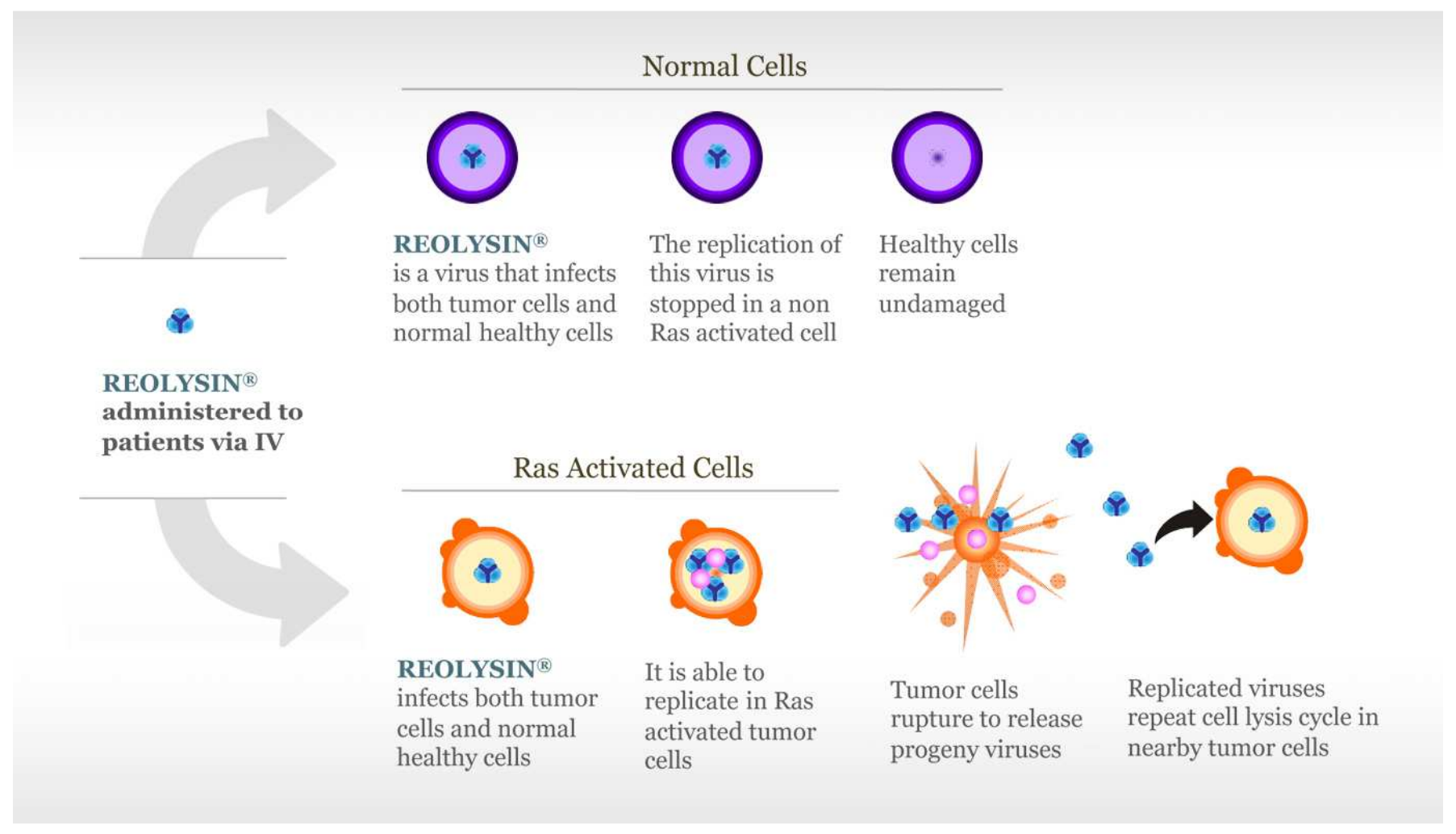

Source: REOLYSIN® Oncolytics Biotech Inc. Viewed on 8th July, $2015<$ http://www.oncolyticsbiotech.com/about-oncolytics/default.aspx>

Fig. 8. Mode of action of Reolysin.

Limitations while using reolysin

1. While the oncolytic virus is well tolerated in patients and local responses were seen in patients with melanoma, head and neck cancer, and Kaposi's sarcoma, evidence for antitumor efficacy at distant sites was not seen.

2. The presence of neutralizing anti-reovius antibody titers associated with the dose of Reolysin administered elicited immune clearance of the reovirus and may have limited its systemic efficacy ${ }^{50}$.

\subsection{Vaccinia Virus}

Vaccinia virus, belonging to the poxvirus family, is an enveloped viral particle that has a linear double-stranded DNA genome regulated by a series of early, early/late, and late viral promoters controlling initial un-coating, DNA replication, and reassembly of immature virion particles. It doesn't cause insertional mutagenesis in a host cell despite of being a DNA virus as its entire life cycle occurs in the cytoplasm in rapid replication cycles.

The large genome size with the presence of nonessential genes, the wide host range, cytoplasmic replication, tissue tropism and vector stability making it an attractive vector for expression of tumor-associated antigens, cytokines, $\mathrm{T}$ cell co-stimulatory molecules, and other genes under the control of a vaccinia promoter.

\subsubsection{Mode of Action}

Poxviruses have biological characteristics that make them particularly promising as oncolytic therapeutics
1. Intravenous stability and efficient delivery to metastatic tumors through the blood

2. Rapid and motile spread within tumors

3. Large transgene-encoding capacity

4. A large safety experience in humans as a vaccine.

Vaccinia virus binds to cell with a cell surface-associated carbohydrate moiety of glycoproteins, heparin sulphate and enters the cell through a micropinocytosis mechanism mimicking an apoptotic bleb, resulting in broad spectrum activity.

The mechanisms due to inherent and engineered properties causing tumor selectivity are:

1. Activation of the EGFR/Ras/MAPK signal transduction pathway and

2. Inactivation of the type-I IFN response pathway.

3. Engineered inactivation of the TK gene

After entering a cell the vaccinia secretes vaccinia growth factor to activate the EGFR/Ras/MAPK pathway or partially inactivate type-I IFNs and inhibitors that block the vaccinia replication. Inactivation of TK gene of vaccinia results on its increased dependence on cellular concentration of TK for replication which is over-expressed in cancer cells.

However, there is a possibility that the tumors could develop a resistance to these inhibitors by initiating the redundant pathways or by activating downstream signalling molecules such as Ras. The JX-594 strain has been developed to be active against EGFR inhibitor-resistant tumors both in vitro and in patients. 


\subsubsection{Vaccinia Viral Strain under Clinical Study}

JX-594

JX-594 (also called PexaVec; Jennerex Inc.) is a vaccinia virus (Wyeth vaccine strain) with TK gene inactivation and insertion of human GM-CSF2 complementary DNA is expressed under the control of a synthetic early-late promoter, and the lac-Z marker transgene is under control of the p7.5 promoter for tumor specificity, immune stimulation and replication assessment, respectively.

Multiple mechanisms of action (MOA) for JX-594 have been demonstrated in preclinical models and patients ${ }^{51}$ :

1. Tumor cell infection and lysis

2. Anti-tumor immune response induction

3. Tumor vascular disruption.

Due to its broad spectrum efficacy against diverse solid tumor types, lung and colorectal Tumor Initiating Cells were also found to be sensitive to JX-594 mediated oncolysis. This is of significance as TICs are known to be generally resistant to currently approved chemotherapies ${ }^{52}$.

JX-594 has been studied in cell lines and in phase 1 and 2 clinical trials with highly positive results of infection and necrosis of even distant tumors by intratumoral and by intravenous administration with transient flu like symptoms. This oncolytic virus class is therefore growing rapidly, and elucidating the selectivity mechanisms that these agents exploit will be critical to maximize patient benefit and the design of future products in this class.

Some of the other advantages of using a vaccinia virus include:

1. Avoiding immune detection and viral clearance in the bloodstream

2. Productive replication in tumor cells; enhanced viral spread

3. Viral-mediated immunogenic cytotoxicity

4. Enhanced tumor infiltration of eosinophils, APC and CTLS

Some limitations of using there are:
1. Minimal inherent tumor selectivity; mild virus related infection

2. Mild virus-related infection

3. Potential for antiviral immunity

4. Stimulates potent cellular and humoral immune response to transgene

\subsection{Newcastle Disease Virus}

Newcastle disease virus (NDV) is an avian virus of the family Paramyxoviridae and genus Avulavirus, with a $15 \mathrm{~kb}$ long single stranded negative sense RNA genome, causes a highly pathogenic disease recognized originally in 1926 at England and as of date causes a deadly infection in both domestic and wild spanning over 250 species of birds, with a range of symptoms, causing major losses to the poultry industry all over the world. Depending on the virulence and severity of disease caused, NDV strains can be divided into three different pathotypes: velogenic (high virulent), mesogenic (mild virulence) and lentogenic (low virulence) strains.

\subsubsection{Molecular Composition}

The virus famil Paramyxoviridae consists of helical capsid symetry. The genome is organized into a non segmented, single stranded RNA of negative polarity. The viral genome, 10-20kb long, codes for 6 gene products: nucleocapsid protein, nucleocapsid associated protein, matrix or membrane protein, fusion protein (Fo uncleaved and F1,2 cleaved), haemagglutinin-neuraminidase and large polymerase protein.

These viruses assemble their capsid in the host cytoplasm and are released via budding thereby coming out with a modified cell membrane envelope. These viral particles generally appear to have a $100-500 \mathrm{~nm}$ diameter and are covered with spike like projections with glycoprotein composition usually $8-12 \mathrm{~nm}$ long which aid in host cell adhesion $^{53}$.

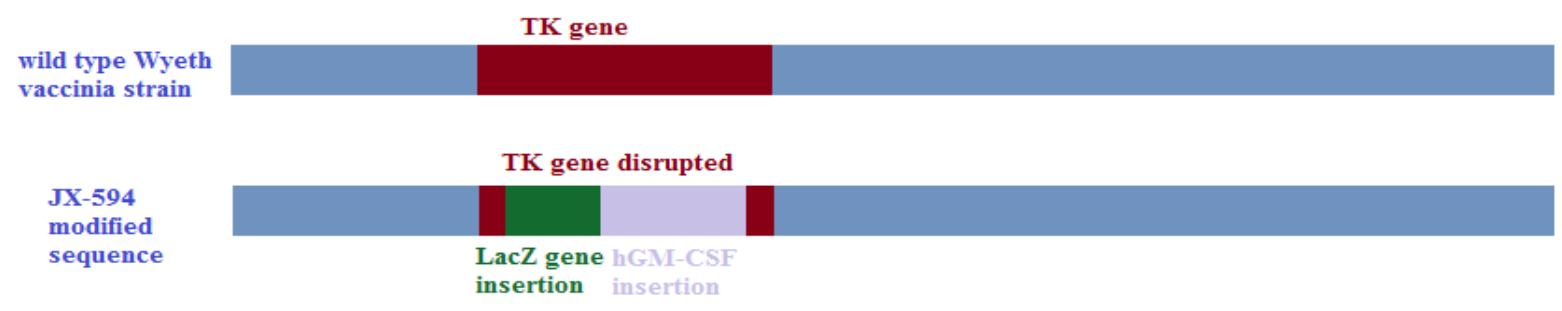

Fig. 9. PexaVec design: targeted and armed vaccinia. 


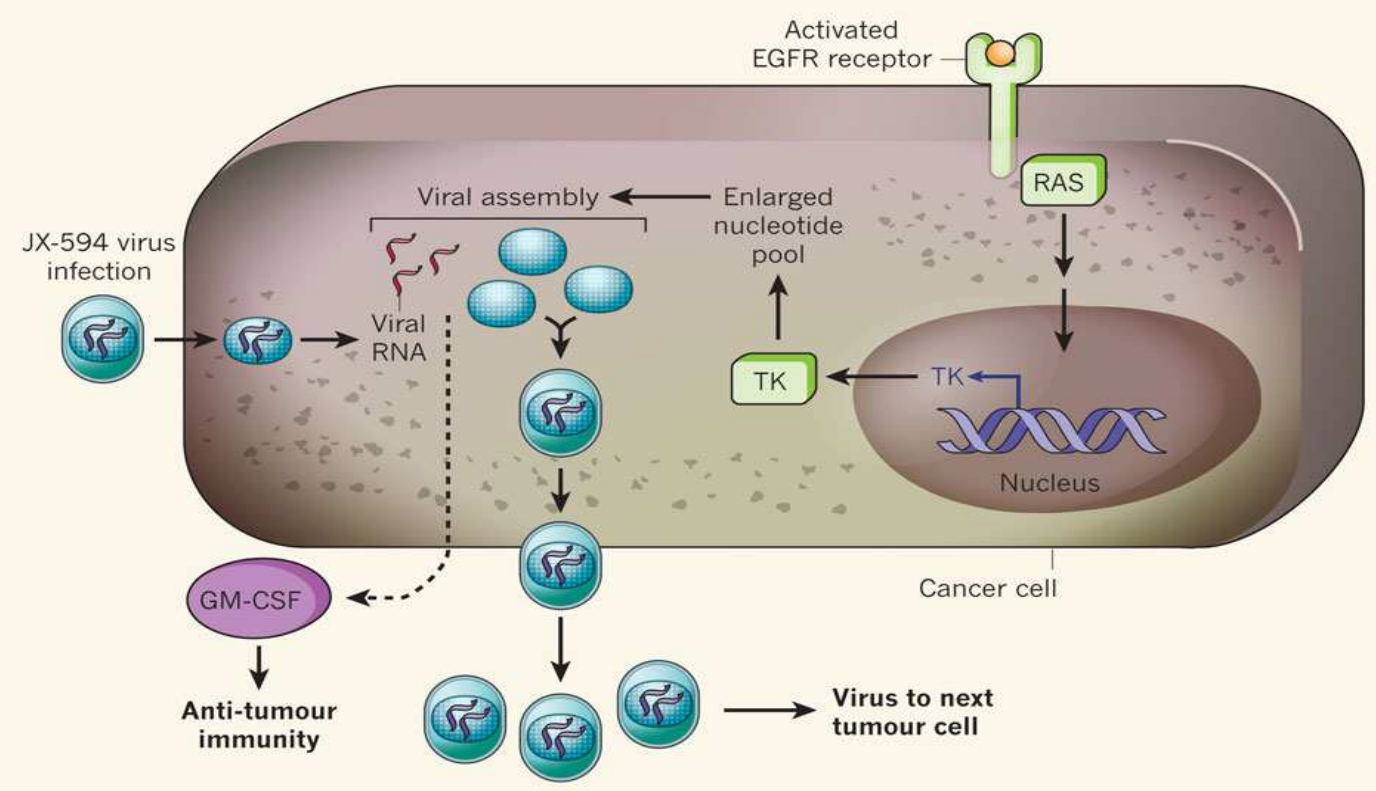

Source: Nature 477.7362 (2011): 40-41.

Fig. 10. Pexa-Vec mechanisms of action

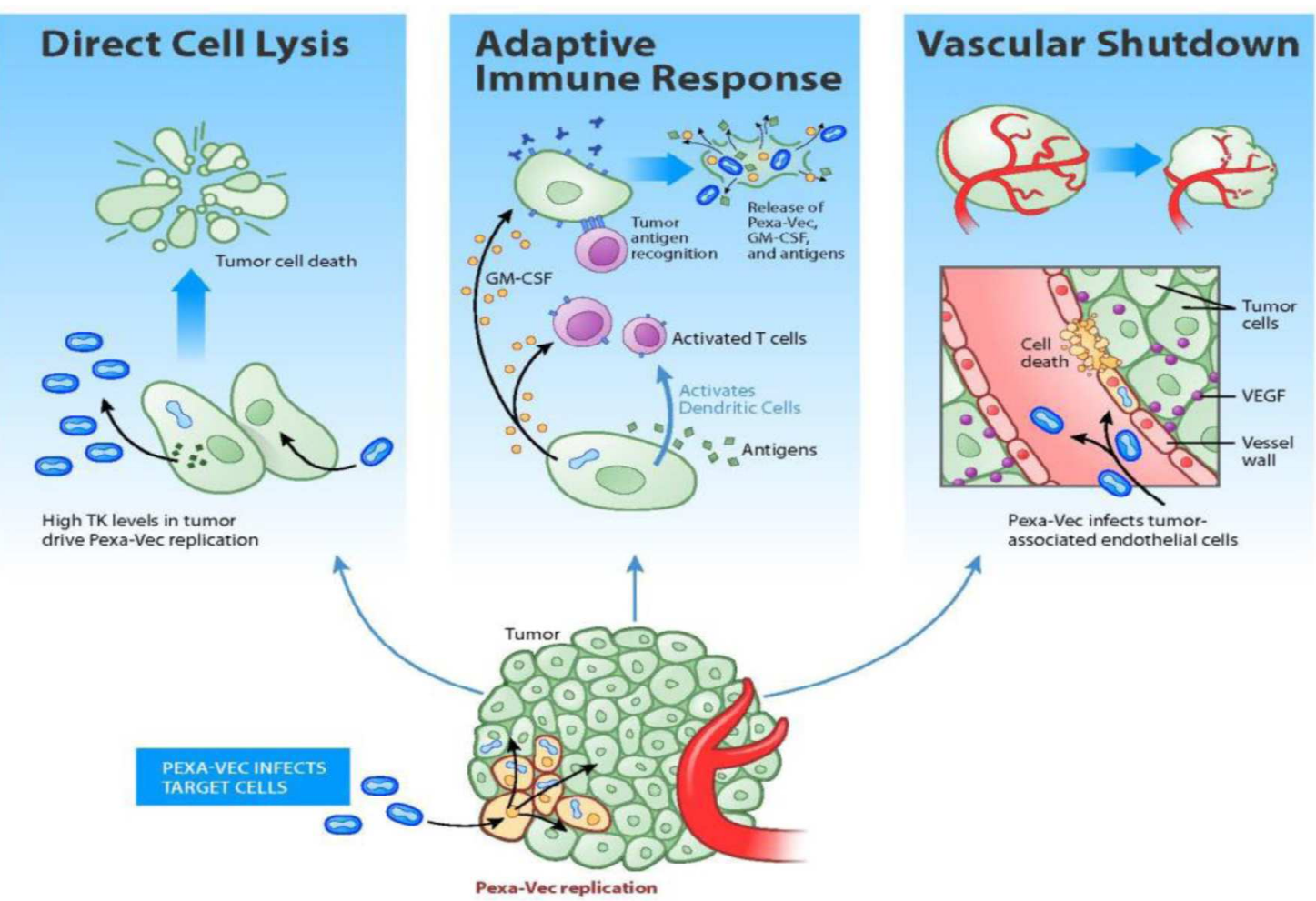

Source: Oncolytic Virotherapy 4 (2015).

Fig. 11. Pexa-Vec mechanisms of action. 


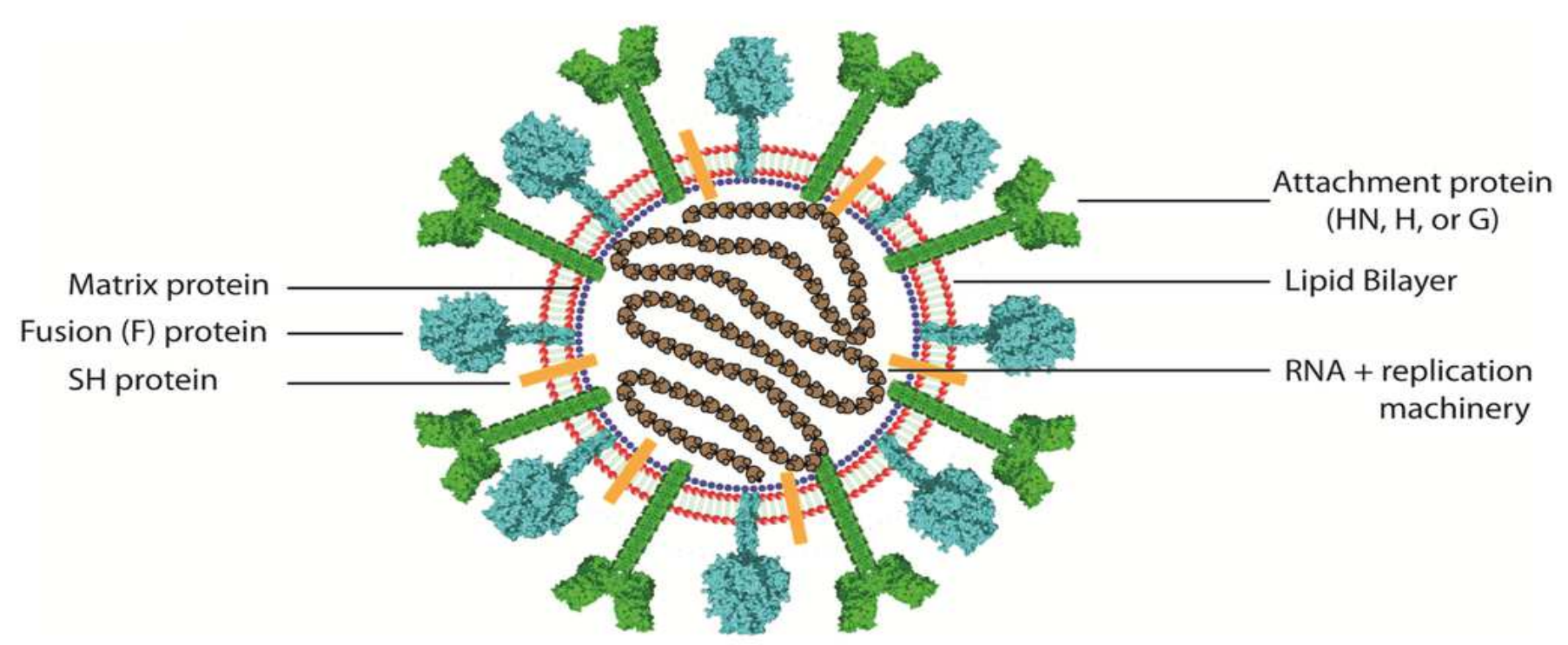

Source: Viruses 4.4 (2012): 613-636

Fig. 12. Structure of a New Castle Disease virus.

NDV infection is facilitated by two glycoproteins: hemagglutinin-neuraminidase (HN) and fusion (F) glycoproteins. HN protein and sialic acid receptors initiate the attachment onto the target cell. This induces a conformational change on $\mathrm{F}$ protein releasing the fusion peptides, fusing viral and cellular membranes. This is followed by uptake of the NDV through endycytosis process.

\subsubsection{Immunostimulatory Property of NDV}

Irrespective of the oncolytic effect, NDV has immunostimulatory properties some of which are summarized in the following table. On delivery of NDV, peripheral blood mononuclear cells (PBMC) cytotoxicity was significantly enhanced with NK cells predominantly causing lysis.

Table 2.2. Summary of the immunological properties of NDV.

\begin{tabular}{ll}
\hline Immunity & Consequences \\
\hline \multirow{2}{*}{$\begin{array}{l}\text { Innate } \\
\text { immunity }\end{array}$} & Cheptotic bodies lead to dendritic cell activation: augmentation of macrophage phagocytosis ability. \\
& Virus progeny resulted in monocyte activation: increased synthesis of NF- $\kappa$, NO, TRAIL, and augmentation of cytotoxic effect. \\
& T cells costimulation: upregulated MHC molecules expression, enhanced antigen presentation, and increased expression of cell adhesion \\
molecules, such as ICAM-1 and LFA-3 molecules. \\
immunity & Expression of viral HN molecules: increased production of IFN- $\alpha$ and TRAIL. \\
& Presence of double-stranded RNA: stimulation of TLR-3, IFN- $\alpha$ and heat shock protein expression.
\end{tabular}

Source: J Biomed Biotechnol. 2011; 2011: 718710. doi: 10.1155/2011/718710

\subsubsection{Anti Cancer Properties of NDV}

Owing to its superior rate of replication in a human neoplastically transformed tumor cell than a normal cell and its oncolytic effects, NDV has gained interest in the scientific population around the world. First reports of its application date back to 1950 s when NDV and adenovirus were used to treat uterine carcinoma resulting in partial necrosis. However this was soon followed by re-growth, probably due to production of neutralizing antibodies against the virus. Many studies were followed exploiting these viral agents with the available technology proving a huge possibility of overcoming different cancers with the oncolytic effects of these viruses.

Some of the advantages of using NDV in cancer treatment are:
1. Recognition of tumor cell surface via its $\mathrm{HN}$ glycoprotein.

2. Enhanced production of viral antigens on tumor cell surface upon viral replication.

3. Stimulates the production of cytokine response, like IFN and TNF, and that of heat shock proteins, adrenocorticotropic hormone, and tissue inhibitor of metalloproteases.

4. Pleiotropic immunostimulatory effects of virus as itcan augment the effects of $\mathrm{T}$ helper $\left(\mathrm{T}_{\mathrm{H}}\right)$ cells, cytotoxic $\mathrm{T}$ lymphocyte (CTL), NK cells, and macrophages.

5. Direct killing of tumor cells or cellular oncolysis.

6. High viral multiplication rate within tumor cells. .

7. Lack of pathogenic activity against humans. 


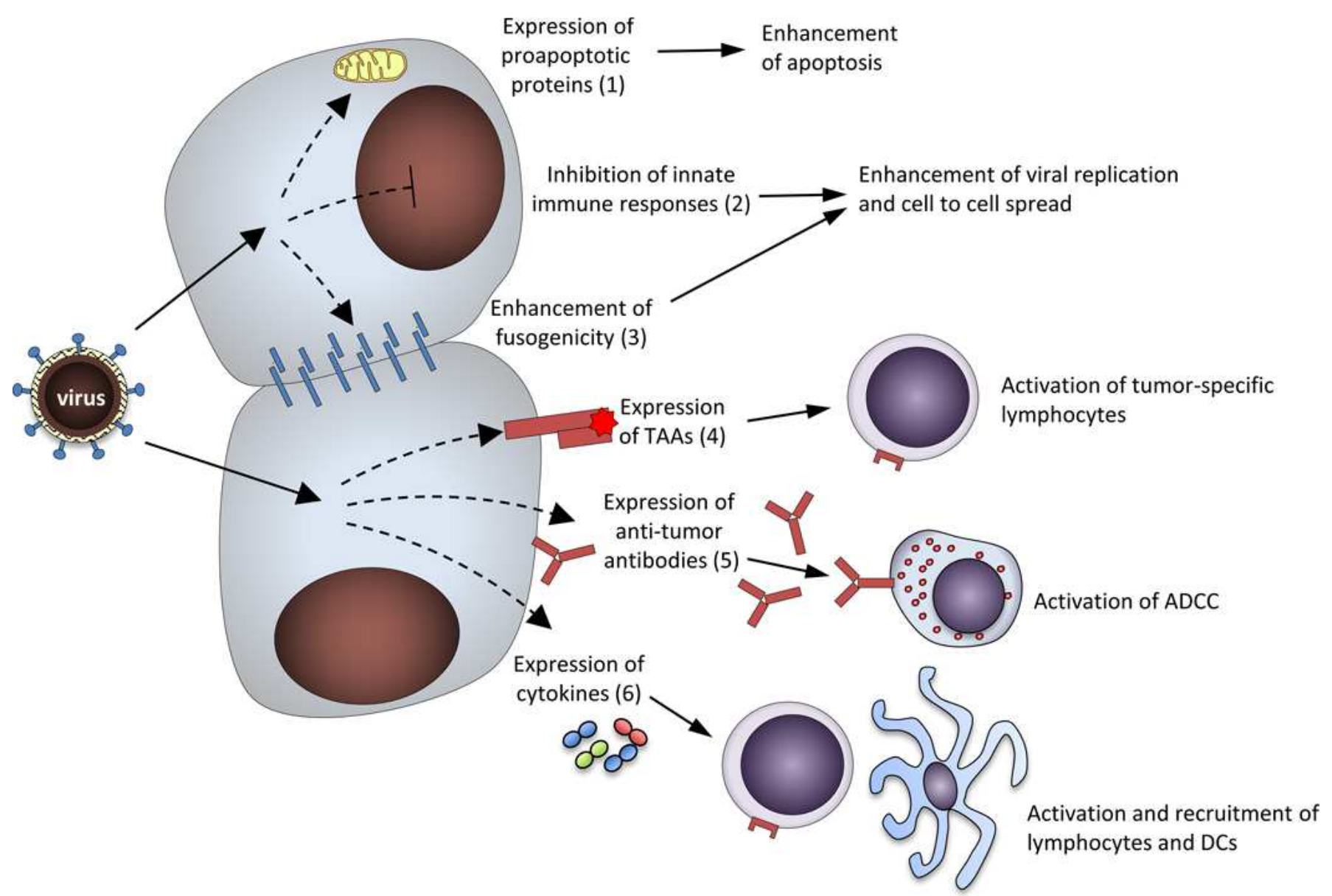

Source: Future microbiology 7.3 (2012): 347-367.

Fig. 13. Strategies employed to enhance anti-tumor activity of NDV via genetic engineering.

\subsubsection{Mode of Action}

NDV mediated cytotoxicity occurs by 2 mechanisms: firstly, by interaction of $\mathrm{HN}$ viral protein with tumor cell surface evoking an immune response and secondly, by local induction of cytokines. ${ }^{54}$

Depending on the mode of oncolysis, NDVs have been evaluated and classified as lytic or non lytic strains. The lytic strains cause syncytia formation to induce changes in the plasma membrane resulting in lysis of target cells. Non lytic strains cause tumor regression slowly by disrupting normal host cell metabolism, preventing further tumor growth without causing lysis.

Non lytic strain such as Ulster, produces non infection viral particles with superior cytotoxic effects in monolayer colon carcinoma cells. Lytic NDV strains such as Italien, MTH68/H, PV-701 and 73-T, cause production of infectious particles that can infect other tumor cells, thus leading to an amplification of the viral load resulting in syncytium promotion and plague generation.

Upon infection, NDV undergoes replication rapidly, releases from the host cell and infects neighboring tumor cells. These have different effects on a tumor cell contributing to its therapeutic properties:

1. The lytic strains of the virus induces lysis and prevents further tumor spread

2. The non lytic strains cause enhanced immunostimulatory response post infection.

3. The virus itself stimulates the production of effector cytokines such as interferons (IFN-ã) or TNFs which activate NK cells, macrophages and sensitized T-cells to kill the tumor cells.

4. Apoptosis

a. NDV induces expression of various cytokines which can activate extrinsic death pathway (involves transmembrane death receptors) causing oncolysis.

b. NDV also augments the expression of induced nitric oxide synthase (iNOS) in infected cells inducing apoptosis also through intrinsic death pathway (non-receptor mediated intracellular signals).

5. NDV induces NFKB and up-regulates the expression of MHC-I genes inducing oncolysis through NFkB pathway.

\subsubsection{Tumor Selectivity}

Initially the selectivity of NDV was proposed to be due to defective IFN type 1 response in tumor cells permitting NDV replication. However, effective oncolytic activity in cancer cell lines possessing a robust IFN response proved that another factor may be responsible for this selectivity. 
Upon infection, NDV has been found to induce apoptosis via mitochondrial pathway activation. This results in opening of mitochondrial permeability transition pores and loss of mitochondrial membrane potential, releasing SMAC/DIABLO and cytochrome cresponsible for suppression of inhibitory apoptosis proteins (IAP) and binding to apoptotic protease activator factor 1 (APAF-1) and procaspase 9 respectively, forming the apoptosome, thereby activating apoptosis. However, if this form of defence mechanism occurs prior to viral assembly, it could prevent further viral infection thereby lowering the net oncolytic effect.

A recombinant NDV strain NDV-NS1, comprising of an anti apoptotic protein NS1 used in a study showed enhanced oncolytic activity demonstrating enhanced NDV replication and fusogenicity allowing neighboring cell fusion and thus enhancing syncytium formation.

Similarly, the anti apoptotic protein $\mathrm{Bcl}-\mathrm{xL}$ is responsible for showing resistance to anti cancer agents. In a study using A549-Bcl-xL cells it was found that NDV- mediated cytolysis and fusogenicity are enhanced compared to those in A549-neo cells. Presence of significantly higher viral titers and viral proteins in A549-Bcl-xL cells than in A549-neo cells indicated that viral replication was enhanced in apoptosis resistant cells. A549-Bcl-xL cells showed an over-expression of Bcl-xL, allowing early NDV replication and production of type 1 IFN thereby inducing activation of apoptosis by antiviral signaling. This subsequently led to higher number of cells being infected during the following viral replication cycles allowing deeper tumor penetration and oncolysis with low initial viral inoculums.

Now, like many other viruses, NDV had developed some mechanisms to delay apoptosis in the infected cells in order to facilitate the viral replication such as the antiapoptotic $\mathrm{v}$ protein blocking the IFN. After initial virus entry, non-cancerous cells quickly undergo apoptosis, resulting in non-productive infection, while apoptosis-resistant cancer cells survive longer, producing more virus particles and initiating new rounds of infection.

Type I IFN has many tumor suppressor effects some of which are mediated through the enhancement of apoptosis induction in cancer cells and cell cycle arrest mediated by many IFN stimulated genes (ISG) or through host-dependent mechanisms including upregulated expression of major histocompatibility complex class I and II molecules, antigen presentation, memory $\mathrm{T}$ cell survival, and $\mathrm{CD} 8^{+} \mathrm{T}$ cell recruitment many of which occur during NDV infection.

All these factors prove NDV mediated oncolysis to be efficient while treating chemoresistant tumors associated with apoptosis resistance. This was proven in a study wherein melanoma showing chemoresistance to IAP Livin was found to undergo oncolysis on administration of NDV-HUJ.

NDV could be used as a form of monotherapy or could be used in conjugation with conventional therapies so as to open the apoptotic pathways and sensitize the cells to the chemotherapeutic agents resulting in a synergic effect ${ }^{55}$.

\section{Conclusion and Future Prospects}

Colorectal cancer is one of the major health concerns in the world being the third most frequently diagnosed cancer in men and women. Conventional chemotherapy or radiotherapy has limited effects against many forms of cancer, not to mention a plethora of treatment-related side effects signifying a need for novel therapeutic strategies, and one such approach is the use of viruses ${ }^{19}$.

This approach is based on exploiting various mechanisms of viruses such as direct lysis, apoptosis, expression of toxic proteins, autophagy and shut-down of protein synthesis, as well as the induction of anti-tumoral immunity. Oncolytic viruses are viruses that are able to replicate specifically in and destroy tumor cells, by the virtue of an inherent or engineered property.

The field of oncolytic virotherapy is expanding and viruses continue to hold promise as effective treatments in combination with chemotherapy or other therapeutic modalities.

Five such viruses, adenovirus, herpes simplex virus, vaccinia virus, reovirus and New Castle Disease virus have been studied as of date to target colorectal cancer cells which can efficiently lyse cancer cells and cancer stem cells, but actively evade the normal unaffected cells.

Even though various barriers yet remain to be crossed, this novel approach is found to be less aggressive, more effective and efficient with minimal side effects than the current modes of therapy, thereby showing a great scope in the future as an actively practiced approach.

\section{References}

[1] Khalek, F. J. A., Gallicano, G. I., \& Mishra, L. (2010). Colon cancer stem cells. Gastrointestinal cancer research: GCR, (Suppl 1), S16.Greaves, L. C., Preston,

[2] Greaves, L. C., Preston, S. L., Tadrous, P. J., Taylor, R. W., Barron, M. J., Oukrif, D., ... \& McDonald, S. A. (2006). Mitochondrial DNA mutations are established in human colonic stem cells, and mutated clones expand by crypt fission. Proceedings of the National Academy of sciences of the United States of America, 103(3), 714-719.

[3] Ricci-Vitiani, L., Fabrizi, E., Palio, E., \& De Maria, R. (2009). Colon cancer stem cells. Journal of Molecular Medicine, 87(11), 1097-1104.

[4] Colorectal Cancer Estimated Incidence, Mortality and Prevalence Worldwide in 2012, globocan.iarc.fr.

[5] Sheiness, D. I. A. N. A., Fanshier, L. O. I. S., \& Bishop, J. M. (1978). Identification of nucleotide sequences which may encode the oncogenic capacity of avian retrovirus MC29. Journal of virology, 28(2), 600-610.

[6] Varmus, H. E. (1985). Alfred P. Sloan prize. Viruses, genes, and cancer. I. The discovery of cellular oncogenes and their role in neoplasia. Cancer, 55(10), 2324-2328.

[7] Bast, R. C., Kufe, D. W., Pollock, R. E., Weichselbaum, R. R., Holland, J. F., \& Frei, E. (2000). Holland-frei cancer medicine. 
[8] Kinzler, K. W., and Vogelstein, B. 2002. Colorectal tumors. In Vogelstein, B., and Kinzler, K. W., eds., The Genetic Basis of Human Cancer (2nd edition)., pp. 583-612. McGraw-Hill, New York.)

[9] Feinberg, A. P., Ohlsson, R., \& Henikoff, S. (2006). The epigenetic progenitor origin of human cancer. Nature reviews genetics, 7(1), 21-33.

[10] Visvader, J. E. (2011). Cells of origin in cancer. Nature, 469(7330), 314-322

[11] Hanahan, D., \& Weinberg, R. A. (2011). Hallmarks of cancer: the next generation. cell, 144(5), 646-674.

[12] Constant, S., Mas, C., Wiszniewski, L., \& Huang, S. (2013). Colon Cancer: Current Treatments and Preclinical Models for the Discovery and Development of New Therapies. INTECH Open Access Publisher.

[13] Bernier, J., Hall, E. J., \& Giaccia, A. (2004). Radiation oncology: a century of achievements. Nature Reviews Cancer, 4(9), 737-747.

[14] Kelly, E., \& Russell, S. J. (2007). History of oncolytic viruses: genesis to genetic engineering. Molecular Therapy, 15(4), 651-659.

[15] www.cancer.org, Accessed on 12th, February 2015

[16] C. Levaditi, S. Nicolau, (1923) "Vaccine et néoplasmes," Ann Inst Pasteur, 37:443-47

[17] Smith, R. R., Huebner, R. J., Rowe, W. P., Schatten, W. E., \& Thomas, L. B. (1956). Studies on the use of viruses in the treatment of carcinoma of the cervix. Cancer, 9(6), 1211-1218.

[18] Asada, T. (1974). Treatment of human cancer with mumps virus. Cancer, 34(6), 1907-1928.

[19] Alemany, R., Balague, C., \& Curiel, D. T. (2000). Replicative adenoviruses for cancer therapy. Nature biotechnology, 18(7), 723-727.

[20] Liu, T. C., Galanis, E., \& Kirn, D. (2007). Clinical trial results with oncolytic virotherapy: a century of promise, a decade of progress. Nature Clinical Practice Oncology, 4(2), 101-117.

[21] Ma, G., Shimada, H., Hiroshima, K., Tada, Y., Suzuki, N., \& Tagawa, M. (2008). Gene medicine for cancer treatment: commercially available medicine and accumulated clinical data in China. Drug design, development and therapy,2, 115.

[22] Vähä-Koskela, M. J., Heikkilä, J. E., \& Hinkkanen, A. E. (2007). Oncolytic viruses in cancer therapy. Cancer letters, 254(2), 178-216.

[23] Russell, S. J., Peng, K. W., \& Bell, J. C. (2012). Oncolytic virotherapy. Nature biotechnology, 30(7), 658-670.

[24] Russell, S. J., \& Peng, K. W. (2007). Viruses as anticancer drugs. Trends in pharmacological sciences, 28(7), 326-333.

[25] Novella, I. S., Gilbertson, D. L., Borrego, B., Domingo, E., \& Holland, J. J. (2005). Adaptability costs in immune escape variants of vesicular stomatitis virus. Virus research, 107(1), 27-34.

[26] Snook, A. E., Magee, M. S., \& Waldman, S. A. (2011). GUCY2C-targeted cancer immunotherapy: past, present and future. Immunologic research, 51(2-3), 161-169.
[27] Schulz, S., Hyslop, T., Haaf, J., Bonaccorso, C., Nielsen, K., Witek, M. E., ... \& Waldman, S. A. (2006). A validated quantitative assay to detect occult micrometastases by reverse transcriptase-polymerase chain reaction of guanylyl cyclase $\mathrm{C}$ in patients with colorectal cancer. Clinical cancer research,12(15), 4545-4552.

[28] Xiang, B., Snook, A. E., Magee, M. S., \& Waldman, S. A. (2013). Colorectal cancer immunotherapy. Discovery medicine, 15(84), 301.

[29] Knijn, N., Mekenkamp, L. J. M., Klomp, M., Vink-Börger, M. E., Tol, J., Teerenstra, S., ... \& Nagtegaal, I. D. (2011). KRAS mutation analysis: a comparison between primary tumours and matched liver metastases in 305 colorectal cancer patients. British journal of cancer, 104(6), 1020-1026.

[30] Makrodouli, E., Oikonomou, E., Koc, M., Andera, L., Sasazuki, T., Shirasawa, S., \& Pintzas, A. (2011). BRAF and RAS oncogenes regulate Rho GTPase pathways to mediate migration and invasion properties in human colon cancer cells: a comparative study. Mol Cancer, 10(1), 118

[31] Duffy, M. J., Van Dalen, A., Haglund, C., Hansson, L., Holinski-Feder, E., Klapdor, R., ... \& Topolcan, O. (2007). Tumour markers in colorectal cancer: European Group on Tumour Markers (EGTM) guidelines for clinical use. European journal of cancer, 43(9), 1348-1360.

[32] Shenk, (2001)"Adenoviridae: The Viruses and Their Replication," in Fields Virology, Vol. 2, Fourth Edition, Knipe, ea., Lippincott, Williams \& Wilkins, pp. 2265-2267

[33] http://www.nlv.ch accessed on 27th Jan, 2015

[34] Patel, M. R., \& Kratzke, R. A. (2013). Oncolytic virus therapy for cancer: the first wave of translational clinical trials. Translational Research, 161(4), 355-364.

[35] Rowan, K. (2010). Oncolytic viruses move forward in clinical trials. Journal of the National Cancer Institute, 102(9), 590-595.

[36] Snook, A. E., Huang, L., Schulz, S., Eisenlohr, L. C., \& Waldman, S. A. (2008). Cytokine Adjuvanation of Therapeutic Anti-tumor Immunity Targeted to Cancer Mucosa Antigens. Clinical and translational science, 1(3), 263-264.

[37] Yang, Z. R., et al. (2007). Recent developments in the use of adenoviruses and immunotoxins in cancer gene therapy. Cancer gene therapy 14.7: 599-615.

[38] Khuri, F. R., Nemunaitis, J., Ganly, I., Arseneau, J., Tannock, I. F., Romel, L., ... \& Kirn, D. H. (2000). A controlled trial of intratumoral ONYX-015, a selectively-replicating adenovirus, in combination with cisplatin and 5-fluorouracil in patients with recurrent head and neck cancer. Nature medicine,6(8), 879-885.

[39] Heise, C., Sampson-Johannes, A., Williams, A., Mccormick, F., Von Hoff, D. D., \& Kirn, D. H. (1997). ONYX-015, an E1B gene-attenuated adenovirus, causes tumor-specific cytolysis and antitumoral efficacy that can be augmented by standard chemotherapeutic agents. Nature medicine, 3(6), 639-645.

[40] Kuhn, I., Harden, P., Bauzon, M., \& Hermiston, T. (2005). 319. ColoAd1, a Chimeric Ad11p/Ad3 Oncolytic Virus for the Treatment of Colon Cancer.Molecular Therapy, 11, S124-S124. 
[41] Kuhn, I., Harden, P., Bauzon, M., Chartier, C., Nye, J., Thorne, S., ... \& Hermiston, T. W. (2008). Directed evolution generates a novel oncolytic virus for the treatment of colon cancer. PLoS One, 3(6), e2409.

[42] Champion, B. R., Kodialbail, P., Illingworth, S., Rasiah, N., Cochrane, D., Beadle, J., ... \& Brown, A. C. (2014). " Arming" the chimeric oncolytic adenovirus enadenotucirev to deliver checkpoint inhibitors and other therapeutics directly to tumours. Journal for immunotherapy of cancer, 2(Suppl 3), P46.

[43] Arvin, A., Campadelli-Fiume, G., Mocarski, E., Moore, P. S., Roizman, B., Whitley, R., \& Yamanishi, K. (Eds.). (2007). Human herpesviruses: biology, therapy, and immunoprophylaxis. Cambridge University Press.

[44] Kolodkin-Gal, D., Zamir, G., Edden, Y., Pikarsky, E., Pikarsky, A., Haim, H., ... \& Panet, A. (2008). Herpes simplex virus type 1 preferentially targets human colon carcinoma: role of extracellular matrix. Journal of virology, 82(2), 999-1010.

[45] Liu, S., Dai, M., You, L., \& Zhao, Y. (2013). Advance in herpes simplex viruses for cancer therapy. Science China Life Sciences, 56(4), 298-305.

[46] Gutermann, A., Mayer, E., Dehn-Rothfelser, K. V., Breidenstein, C., Weber, M., Muench, M., ... \& Lechmann, M. (2006). Efficacy of oncolytic herpesvirus NV1020 can be enhanced by combination with chemotherapeutics in colon carcinoma cells. Human gene therapy, 17(12), 1241-1253.

[47] Thompson, B. G., \& Coffey, M. C. (2012). U.S. Patent No. $8,222,036$. Washington, DC: U.S. Patent and Trademark Office.
[48] Vidal, L., Pandha, H. S., Yap, T. A., White, C. L., Twigger, K., Vile, R. G., ... \& DeBono, J. S. (2008). A phase I study of intravenous oncolytic reovirus type 3 Dearing in patients with advanced cancer. Clinical Cancer Research, 14(21), 7127-7137.

[49] Carew, J. S., Espitia, C. M., Kelly, K. R., Coffey, M., Freeman, J. W., \& Nawrocki, S. T. (2012). Reolysin: A novel reovirus-based agent that induces endoplasmic reticular stress in RAS-activated pancreatic cancer. Cancer Research, 72(8 Supplement), 2717-2717.

[50] Goldufsky, J., Sivendran, S., \& Pan, M. (2013). Oncolytic virus therapy for cancer. Oncolytic Virotherapy, 2, 31-46.

[51] Breitbach, C. J. (2015). The emerging therapeutic potential of the oncolytic immunotherapeutic Pexa-Vec (JX-594).

[52] Conrad, S. J., \& Essani, K. (2014). Oncoselectivity in Oncolytic Viruses against Colorectal Cancer. Journal of Cancer Therapy, 5(13), 1153.

[53] Alexander, D. J., \& Alexander, D. J. (Eds.). (1988). Newcastle disease (Vol. 8). Springer Science \& Business Media

[54] Lam, H. Y., Yeap, S. K., Rasoli, M., Omar, A. R., Yusoff, K., Suraini, A. A., \& Banu Alitheen, N. (2011). Safety and clinical usage of Newcastle disease virus in cancer therapy. BioMed Research International, 2011.

[55] Mansour, M., Palese, P., \& Zamarin, D. (2011). Oncolytic specificity of Newcastle disease virus is mediated by selectivity for apoptosis-resistant cells. Journal of virology, 85(12), 6015-6023. 